\title{
Od kod slovenski dendronim jâm »brest«?
}

\author{
Helena Jazbec, Metka Furlan (Ljubljana)
}

IZVLEČEK: Slovenske dendronime jâm »brest«, jân »isto« in läm se izvaja iz srednjevisokonemške predloge, ki se ohranja v bav. nvn. Alme »brest«.

ABSTRACT: The Slovenian dendronyms jâm, jân, and läm (all 'elm') derive from a Middle High German base preserved in Bavarian NHG Alme (elm).

1. $\mathrm{Za}^{1}$ drevesno vrsto Ulmus imamo v slovenščini ob splošno znanem brẹ́st še vrsto podobnozvočnih izrazov, pri katerih upravičeno lahko domnevamo, da so etimološko povezani, a so v slovenščini deloma izposojeni, deloma pa podedovani iz praslovanščine. Maks Pleteršnik v svojem Slovensko-nemškem slovarju navaja jâm »brest«, jámovəc, gen. -vca »isto«, jân, lìm, gen. líma, lom, ilmovəc, gen. -vca in ilom, gen. ilma. V Etimološkem slovarju slovenskega jezika pa France Bezlaj dodaja še läm, lemovec in lemkovec (ESSJ, II, 142), ki so verjetno posredno povzeti iz Šulekovega slovarja fitonimov (Šulek 1879, 189, 193). Slovenske dendronime lam, lemovec in lemkovec namreč Šulek brez naglasnih oznak navaja po gradivu, ki mu ga je Henrik Freyer predal leta 1850 in vsebuje predvsem fitonime s Kranjske (Šulek 1879, XIV-XV). Različica imovec, ki je tudi navedena v ESSJ, 1. c., je verjetno povzeta iz Brinarjevega Gozdarskega slovarja, ki navaja ímovec »gorski brest, Ulmus scabra« (Brinar 1970, 76). Ta dendronim je izpeljanka tipa jâm $\rightarrow$ jámovəc iz različice 'i:m, ki je še živa v štajerskih govorih Zadrečke doline (Weiss 1998, 108). ${ }^{2}$

1 Besedilo je bilo pripravljeno z vnašalnim sistemom ZRCola, ki ga je na Znanstvenoraziskovalnem centru SAZU v Ljubljani (http://www.zrc-sazu.si) razvil Peter Weiss.

2 Fonem tega dendronima je posredoval P. Weiss, ustno. 
2. Vse te dendronime lahko glede na fonetično podobo in njihov možen izvor razdelimo na štiri skupine.

2.1. Različice iləm, ilmovəc, po zgodnji asimilaciji - $l m->-m^{3}{ }^{3}$ 'i:m (Zadrečka dolina), ímovec in po internoslovenskem premetu lim, gen. líma s skupno slovensko osnovo *ilm- so lahko dediščina iz psl. *jblımь ${ }^{4}$ (Bezlaj ESSJ, II, 142; ĖSSJ, 8, 222-3), čeprav bi enako fonemsko zaporedje *ilm- imela tudi izposojenka iz srvn. ilm (f.) »brest «. ${ }^{5}$ Ker varianta iləm do sedaj v narečjih ni bila potrjena in je bila zabeležena pozno, v drugi polovici 19. stoletja, v Cigaletovem in Janežičevem slovarju, je možno, da je bila umetno uvedena na podlagi r. ílem, gen. ílbma »Ulmus« (Pleteršnik 2006, 291; Berneker 1908-1913, I, 424).

2.2. Če samo iz Freyerjevega rokopisnega gradiva potrjeni varianti lemovec in lemkovec nista morda le zapisa za reducirani obliki *lomovəc in *lomkovəc (iz sln. *lim(k)óvəc), kot nakazuje obirsko koroško lomó:wc, gen. -a »brest« (Karničar, 157) in iz Planine nad Jesenicami posredovano Imóvěc (Pintar, 21), se v njiju lahko ohranja psl. dendronimu $* j b l(b) m ъ$ variantni in sorodni *elmъ, ${ }^{6} \mathrm{ki}$ ga Schuster-Šewc, 859, predpostavlja iz dl. lom »Ulmus«, ukr. lьom »isto《 in br. lëm »Ulmus foliacea«, prim. še r. nar. lëmok»mladi brest« (ÈSSJ, 8, 222-223).

2.3. Varianta lom, ki jo Pleteršnik navaja po Mateju Cigaletu in Oroslavu Cafu, kot slovenska, povzeta po Freyerjevem gradivu, pa je bila zabeležena tudi v Šulekovem slovarju (Šulek 1897, 203), je zaradi preohlapnih podatkov o arealu še težje razložljiva. Bezlajeva razlaga, da naj bi bila ta, tako kot druge pri njem omenjene dendronimske različice v slovenščini, bolj verjetno praslovanska dediščina, kot pa izposojena iz srvn. ilm »Ulmus« (Bezlaj ESSJ, II, 142), je nezadostna.

2.4. V četrto skupino pa smemo uvrstiti različice jâm, jámovəc, jân in tudi läm, kot se bo izkazalo v nadaljevanju.

3. Pričujoči članek skuša v prvi vrsti razložiti nastanek in izvor variant iz zadnje

3 Relativna kronologija asimilacije v zgodnjo plast tipa sonce $\leftarrow$ solnce (Ramovš 1924, 39) je postavljena zaradi tpn Ímovica »naselje v občini Lukovica pri Domžalah«, v katerem se ta dendronim po vsej verjetnosti ohranja in je bil že leta 1384 zabeležen kot Ymowitz (Kos 1975, 215).

4 Ob domnevi, da je drugi polglasnik v psl. *jblbmъ »Ulmus«, na katerega nedvomno kaže npr. p. ilm, sekundaren, bi bilo v psl. *jblms možno prepoznati popolno paralelo z lat. ulmus »brest«, oboje pa izvajati iz praide. ${ }^{*} H_{l} l m-o ́-s$. Glej tudi op. 6.

5 Domnevo o nemškem izvoru slovanskih dendronimov, ki se jih danes pretežno razlaga kot praide. dediščino iz psl. *jblımb (ÈSSJ, 8, 222-3), je postavil Miklošič 1886, 95, sprejel pa Berneker 1908-1913, I, 424. Dalje glej op. 11.

$6 \mathrm{~V}$ psl. dendronimu *elmъ »Ulmus« bi bilo možno prepoznati paralelo s stvn. elmo »U1mus«, elm »isto« iz praide. ${ }^{*} H_{1}$ élm-o-s. Razmerje ${ }^{*} H_{1}$ élm-o-s : ${ }^{*} H_{l o} l m-o ́-s$ lahko odraža prvotni konzonantni samostalnik s paradigmo ${ }^{*} H_{l}$ élōm, gen. ${ }^{*} H_{l o} l m$-és, lok. ${ }^{*} H_{l} l e ́ m$, pa-

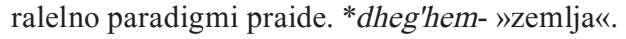


omenjene skupine, predvsem jâm »brest« s tvorjenko s sestavljeno pripono -ov-ec jámovac ${ }^{7} » b r e s t \ll$ in jân. Te v etimoloških slovarjih še niso bile obravnavane.

3.1. V geslu jâm »brest« Pleteršnik 2006, 355, opozarja, da naj bi to bila izposojenka iz tirol. nem. ilm (f.) »Ulmus « (Schöpf 1982, 286), kar zaradi razlike v fonetični podobi nemške predloge ne prepričuje.

Pleteršnik po Cafovem slovarskem gradivu navaja, da je dendronim jâm znan v mariborski okolici, po Erjavčevem gradivu iz Pótne torbe iz leta 1879 pa tudi v Sevnici na Štajerskem (Erjavec 1879, 121). Različico jân je Caf poznal iz Frama na Štajerskem, jámovoc pa iz Slovenj Gradca na Koroškem. Širši areal tega dendronima potrjuje terski jám »brest«, ki ga tako onaglašenega omenja Pavle Merkù, ko iz njega izvaja terski mikrotoponim Potjám pri Zavarhu v občini Bardo/ Lusevera (Merkù 2006, 159).

Zaradi fonetičnega neujemanja sln. jâm ne moremo izvajati iz tirol. nem. predloge ilm »Ulmus«, ampak je bolj verjetno, da se v njem odraža slovenski substitut iz srvn. predloge, ki še živi v bavarskem nvn. Alme »Ulmus« (Marzell 1943-1958, IV, 903). Tako relativno kronologijo izposoje iz srvn. *alme »Ulmus« = bav. nvn. Alme je potrebno predpostaviti zaradi areala slovenskih dendronimov in znakov, ki kažejo, da je do izposoje prišlo v času pred narečnim podaljšanjem skrajšanega psl. starega akuta v enozložnicah tipa brät $\rightarrow$ 'bra:t.

Čeprav se vključno do 16 . stoletja $^{8}$ nemški izglasni in predkonzonantni $l \mathrm{v}$ slovenščino še prevzema kot trdi $1,{ }^{9}$ je bila predloga za narečno jâm v slovenščino prevzeta prej, iz srednjevisokonemškega ustreznika *alme »Ulmus« za bav. nem. Alme. V slovenščini je bila ta srvn. predloga s kratkim vzglasnim zlogom po vzorcu krämp »orodje za kopanje« $\longleftarrow$ srvn. krampe (Grafenauer 1923, 372) prevzeta kot sln. *äłm in se je vključila v deklinacijski tip brät, gen. b'rá:ta, ki se ga glede podaljšave skrajšanega psl. starega akuta v nezadnjem besednem zlogu postavlja v konec 14. stoletja (Ramovš 1950, 21). V nadaljnjem slovenskem razvoju se je konzonantna skupina - $ł m$ - poenostavila $v-m$ - po vsej verjetnosti še pred prehodom ı> un: sln. *äłm > *äm. Primeri iz Ramovševega Konzonantizma (1924, § 25, § 34) sicer kažejo, da do takih asimilativnih izpadov predkonzonantnega $\nmid$ lahko pride samo za $o$-jem ali $u$-jem: ọhrovt $<$ sln. *ołhrout $\leftarrow$ bav. srvn. *kôlkrout, bav. nvn. Kohlkraut »zelje, ohrovt«; špọgati (si) »uporabljati; privoščiti si« < sln. * špołgati $\leftarrow$ srvn. spulgen »biti navajen, uporabljati« (Ramovš 1924, § 25; Striedter-Temps, 185, 225). Vendar nam na možnost enakega pojava pred a-jem kaže npr. obirsko koroški pridevnik há:mužən, f. -žna »V srce segajoč, nesposoben, slaboumen« (Karničar, 117), v katerem se ohranja starovisokonemška izposojenka v slovenščini álmožna »miloščina« (Striedter-Temps, 80).

Vzglasni j-v jâm je torej protetičen kot npr. v nemških izposojenkah jamati »izmeriti vsebino soda $\mathrm{z}$ odčitalno palico, tj. $\mathrm{z}$ amo« $\longleftarrow$ âmati »isto« ali bkr. jásla

7 Besedotvorni postopek je pravzaprav sledeč: jam »brest «+ -ov = jamov »brestov«; jamov $+-e c=$ jamovec $» b r e s t \ll$. Pridevnik jámov »brestov« navaja Pleteršnik.

8 Začetek nove visoke nemščine se datira $\mathrm{z}$ letom 1500.

9 Po 16. stoletju smo nemški izglasni in predkonzonantni 1 prevzemali s $\operatorname{sln}$. srednjim 1 (Striedter-Temps, § 112-120). 
$\exists \quad$ »ognojek, tvor, čir« $\leftarrow$ ásla »ognojek, uljé, tvor, čir, prisad v rani« (Striedter-Temps, 81, 84; Bezlaj ESSJ, I, 4, 6).

3.2. Različica jân »Ulmus«, ki je znana samo iz Frama na Štajerskem, ni mogla po slovenskem fonetičnem razvoju nastati iz jâm, ker tam razvoj $-m>-n$ ni znan. Izglasni - $n$ v jân je v odnosu do jâm možno razložiti z nemško fonetiko. V bavarščini je razvoj izglasnega $-m>-n$ pogost, prim. bav. nvn. Qtn za širše nvn. Atem, srvn. âtem»sapa, dih« (Striedter-Temps, § 132; Kranzmayer 1956, § 48b). Sln. substitucijo - $n$ za bavarski $-n<-m$ izkazuje npr. sln. pûšpan »Buxus sempervirens « $\leftarrow$ bav. srvn. *puhśpān < bav. srvn. puhśpām »isto« (Striedter-Temps, 205). Na podlagi tega bavarskega fonetičnega pojava in pogoste apokope v nemščini, ki jo pri tej nem. besedni družini potrjuje npr. švicarsko nem. Olm »Ulmus« (Marzell 1943-1958, IV, 903), je možno predpostaviti, da je v bav. srvn. obstajal dendronim *aln »Ulmus « $(<*$ alm $<* A l m e)$, ki je bil v slovenščino prevzet verjetno sočasno kot srvn. sinonim *alme in oba substituta *äłm in *äłn sta se v nadaljnjem slovenskem razvoju obnašala enako:

\section{sln. *âłm $>*$ âm $>*$ j-äm $\operatorname{sln} . *$ äłn $>* a ̈ n ~>* j$-än}

3.3. V luči razlage nastanka in izvora sln. jâm in jân je smiselno dopolniti Bezlaja ESSJ, II, 142, ki za sln. läm»Ulmus«, tako kot za vse druge enakopomenske različice, ki jih obravnava, domneva, da so praslovanska dediščina v slovenščini. Za sln. läm, ki z redukcijo v imenovalniku kot 'lęm z gen. lá:ma, lá:mę »brest« še živi v bovškem govoru (Ivančič 2000, 40), je namreč bolj verjetno, da tako kot jâm odraža izposojenko iz iste srvn. predloge, le da je bil slovenski substitut *äłm podvržen premetu, kar je dalo läm. Pojav je pri obravnavanih dendronimih razviden iz razmerij ilmovəc: lìm, potrjuje pa ga tudi drugo domače gradivo, kot je razvidno iz sln. sołza $>$ sloza; $\ln$. dołgo $>*$ dłogo $>$ zilj. dwogo; sln. kolnica »pokrit

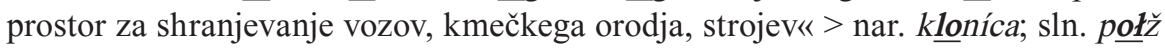

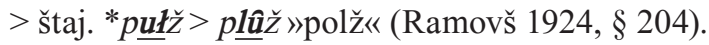

3.4. Iz razlage, da se v narečnih dendronimih jâm (štaj.), jân (Fram) in läm = bovško 'lęm, gen. lá:ma/lá:me ohranja srednjevisokonemška izposojenka *äłm z varianto *äłn, je razvidno, da imata štajerski enozložnici dolg vokal, internoslovensko podaljšan po tipu brät $\rightarrow$ b'ra:t, prvotna kračina pa je še ohranjena v läm = bovško 'lęm. Iz sistema pričakovanih kvantitetnih razmerij izstopa le terski dolg vokal v jám. Tu bi zaradi izglasnega $-n<\operatorname{sln}$. $-m$ na širšem zahodnem območju pričakovali refleks *'jan s kračino kot npr. v p'rax = knjiž. präg (Šekli 2006, 169). Izglasni $-m$ bi bilo $\mathrm{v}$ terskem jám sicer možno razložiti kot sandhi varianto iz prvotnega terskega $*^{\prime} j a n^{10}$, sporočena dolžina v enozložnici namesto pričakovane kračine pa bi še vedno ostala nepojasnjena.

\subsection{Osamljena varianta lom lahko izvira iz slovenskega narečnega sistema z}

${ }^{10}$ O tem pojavu na skrajnem zahodnem območju Furlan 1991, 26. 
ohranjeno kračino v tipu brät in lahko predstavlja vokaliziran refleks reducirane oblike, ki je nastala ali po redukciji kratkega a v əiz läm ali pa po redukciji kratkega i v ə iz lim: ${ }^{11}$

$$
\text { lom }<\text { *ləm }<\text { läm/lìm }
$$

4. Za konec si oglejmo bav. nvn. Alme »Ulmus«, nemško predlogo za sln. izposojenke jâm, jámovəc, jân, läm in morda tudi lom. Nemški etimološki slovarji razlagajo izvor nvn. različic Elm(e) (f.), IIm(e), Ulme in Olme (<Ulme), različice nvn. Alme ( $>$ Olme) pa ne omenjajo. Tako kot lahko ugotavljamo v slovenščini, so tudi v nemščini različice delno izposojene, delno pa dediščina iz pragermanščine. Nvn. Elm(e), Ilm(e), srvn. elm(e), elmboum, ilmboum, stvn. elmo, elm, elmboum, ilma Pfeifer izvaja iz praide. samostalnika *elem- s korenom *el-, *ol- »rdeč, rjav«, s katerim naj bi bil brest poimenovan po barvi sveže posekanega rdečerjavega lesa (Pfeifer, 1482). Nvn. Ulme in iz tega Olme pa je bilo v nemščino izposojeno iz lat. ulmus »brest« (ibid.)

Bavarska nvn. različica Alme je iz Elme lahko nastala pod vplivom vzglasja bav. nvn. Alber, ker ta dendronim ob »topol, Pappel« lahko pomeni tudi »brest« (WBMÖ, 3, 132). Formalna kontaminacija Elme v Alme na podlagi Alber pa je po drugi strani sprožila, da so narečni refleksi Alme ponekod začeli označevati topola, npr. bavarsko narečje na Moravskem pozna labializirano različico $\bar{Q} l m$ »beli topol, Weißpappel« (<*alm), nemško narečje na Gradiščanskem pa Q̄lme »topol, Pappel« (WBMÖ, 3, 132). Areal te nemške izposojenke v slovenščini in naglasna razmerja $\mathrm{v}$ njej pa vodijo k domnevi, da je do kontaminacije in nastanka različice Alme prišlo vsaj že v srednji visoki nemščini. Takemu sklepu nemško gradivo ne nasprotuje, saj je dendronim Alber kot albari obstajal že v stari visoki nemščini (Kluge-Seebold, 24).

\section{Okrajšave jezikov/narečij}

bav. $=$ bavarsko, bkr. $=$ belokranjsko, br. $=$ belorusko, dl. $=$ dolnjelužiško, gen. = genitiv, lat. = latinsko, nar. = narečno, nem. = nemško, nvn. = novovisokonemško, p. $=$ poljsko, praide. $=$ praindoevropsko, psl. $=$ praslovansko, r. $=$ rusko, sln. $=$ slovensko, srvn. = srednjevisokonemško, stvn. = starovisokonemško, štaj. = štajersko slovensko, tirol.= tirolsko, ukr. = ukrajinsko, zilj. = ziljsko

${ }^{11}$ Sln. dendronime, ki jih je mogoče izvajati iz prvotnega sln. *iłm (npr. ímovec (Brinar), 'i:m (Zadrečka dolina), lim, gen. líma (Plužna, Trenta; Pleteršnik 2006, 515)), bi bilo zaradi naglasnih razmer kljub Bezlaju ESSJ, II, 142, bolje razlagati kot nemške izposojenke iz srvn. ilm »brest« $\rightarrow$ sln. *ïłm. V Kanalski dolini izpričana oblika lìma »Ulmus glabra« (Oman 1992, 51) kaže, da je pri vzorcu prevzema srvn. ilm (f.) nad fonetično podobo predloge prevladal spol besede, ki je povzročil substitucijo s sln. *iłma (f.). Podoben dvojni vzorec prevzema odražata npr. srednjevisokonemški izposojenki márter (m.), gen. -tra »trud, napor« (nižje pogovorno) in mârtra (f.) »trpljenje, bolečina« (starinsko; oboje SSKJ) iz srvn. marter(e) (f.) »trud, napor, bolečina« (Striedter-Temps, 177). 


\section{$4 \quad$ Literatura in viri}

Bergmann, H., Pohl, H. D., 2002, Die Namen der Karnischen Alpen. Teil I: Kärntner Anteil (von Steinkarspitz bis Plöckenpass). Gemeinden Lesachtal und Kötschach-Mauthen, Kärnten. Hrsg. P. Anreiter (= Beihefte zur Österreichischen Namenforschung 2), Wien, Ed. Praesens.

Berneker, E., 1908-1913, Slavisches etymologisches Wörterbuch I-II. Heidelberg, C. Winter's Universitätsbuchhandlung.

Bezlaj ESSJ = Bezlaj, F., 1976-2005, Etimološki slovar slovenskega jezika I-IV, Avtorji gesel F. Bezlaj, M. Furlan in M. Snoj, Ljubljana, Mladinska knjiga, ZRC SAZU.

Brinar, M., 1970, Gozdarski slovar, Ljubljana, Zveza inženirjev in tehnikov gozdarstva in industrije za predelavo lesa Slovenije.

Cigale, M., 1860, Deutsch-slovenisches Wörterbuch I-II, Laibach.

Erjavec, F., 1879, Iz pótne torbe, V: Letopis Matice slovenske za leto 1879, Ur. J. Bleiweis, Ljubljana, Matica Slovenska.

ÈSSJ = Trubačev, O. N. (red.) 1974-, Ėtimologičeskij slovar' slavjanskich jazykov. Praslavjanskij leksičeskij fond I-. Moskva, Izdatel'stvo »Nauka« Akademija Nauk SSSR.

Furlan, M., 1991, Slovensko slima »faliua, plouagne« (Alasia) in srbohrvaško slîm (Žumberek) - novo gradivo za slovansko-germansko izogloso *slímъ : *slīma- Jezikoslovni zapiski 1, 25-30.

Grafenauer, I., 1923, Naglas v nemških izposojenkah (Donesek k zgodovini slovenskega naglasa) - Razprave $Z D H V$ I, Ljubljana, Znanstveno društvo za humanistične vede v Ljubljani.

Ivančič, B., 2000, Diferencialni slovar bovškega govora, Seminarska naloga na magistrskem študiju, Mentorica Vera Smole, Rokopis, Ljubljana.

Janežič, A., 1867, Deutsch-slovenisches Taschen-Wörterbuch für Schule und Haus. 2., umgearb. und vermehr. Auflage. Klagenfurt, E. Liegel's Buchhandlung.

Karničar, L., 1990, Der Obir-Dialekt in Kärnten. Die Mundart von Ebriach/Obirsko. Wien, Verlag der Österreichischen Akademie der Wissenschaften.

Kluge-Seebold, E., 1995, Kluge - Etymologisches Wörterbuch der deutschen Sprache. Bearbeitet von E. Seebold, 23., erweiterte Auflage, Berlin, New York, Walter de Gruyter.

Kos, M., 1975, Gradivo za Historično topografijo Slovenije (za Kranjsko do leta 1500) I-II, Ljubljana.

Kranzmayer, E., 1956, Historische Lautgeographie des gesamtbairischen Dialektraumes, Wien.

Marzel1, H., 1943-1958, Wörterbuch der deutschen Pflanzennamen I-V, Unter Mitwirkung von W. Wissmann. Leipzig, S. Hirzel.

Merkù, P., 2006, Krajevno imenoslovje na slovenskem zahodu, Uredila Metka Furlan in Silvo Torkar, Zbirka: Lingustica et philologica 15, Ljubljana, Založba ZRC, ZRC SAZU.

Miklošič, F., 1886, Etymologisches Wörterbuch der slavischen Sprachen. Wien, W. Braumüller. 
Oman, A., 1992, Etnobotanica della Val Canale. Con particolare riguardo ai fitonimi sloveni di Ugovizza, Valbrunna e S. Leopoldo. Čedad v Furlaniji, Società Cooperativa Editrice Dom.

Pfeifer, W., 2000, Etymologisches Wörterbuch des Deutschen, München, DTV.

Pintar, L., 1895, Slovarski in besedoslovni paberki, Letopis Slovenske matice za leto 1895, str. 1-52. Ljubljana, Slovenska matica.

Pleteršnik, M., 2006, Slovensko-nemški slovar I-II. CR-ROM. Transliterirana izdaja. Uredila M. Furlan. (Original izšel 1894-5). Ljubljana, Založba ZRC, ZRC SAZU.

Ramovš, F., 1924, Historična gramatika slovenskega jezika II. Konzonantizem. V Ljubljani, Učiteljska tiskarna.

Ramovš, F., 1950, Relativna kronologija slovenskih akcentskih pojavov-Slavistična revija III, 16-23.

Schöpf, J. B., 1982, Tirolisches Idiotikon. Nach dessen Tode vollendet von A. J. Hofer. Neudruck der Ausgabe 1866, Schaan/Liechtenstein, Sändig Reprint Verlag.

Schuster-Šewc, H., 1978-89, Historisch-etymologisches Wörterbuch der ober- und niedersorbischen Sprache, Bautzen, VEB Domowina.

SSKJ, 1970-1991, Slovar slovenskega knjižnega jezika I-V, Ljubljana, Državna založba Slovenije.

Striedter-Temps, H., 1963, Deutsche Lehnwörter im Slovenischen. Berlin: Osteuropa-Institut.

Šekli, M., 2006, Tersko narečje v kraju Subid, Terska dolina/Alta Val Torre/Val de Tor, Terska dolina $v$ besedi, sliki in pesmi Viljema Černa, Uredila/A cura di Milena Kožuh, Celje - Gorica, Celjska Mohorjeva družba in Goriška Mohorjeva družba, str. 161-170.

Šulek, B., 1879, Jugoslavenski imenik bilja, Zagreb, JAZU.

WBMÖ = Bayerisch-österreichisches Wörterbuch I-, Österreich, Wörterbuch der bairischen Mundarten in Österreich. Wien, Österreichische Akademie der Wissenschaften, 1963-.

Weiss, P., 1998, Slovar govorov Zadrečke doline med gornjim Gradom in Nazarjami, Poskusni zvezek A-H, Ljubljana, ZRC SAZU, Založba ZRC.

\section{The Origin of the Slovenian Dendronym jâm 'elm'}

Summary

This article seeks to explain the creation and origin of the Slovenian terms for Ulmus jâm and jân. The dendronym jâm is known in the Maribor area and in Sevnica (Styria), the variant jân is known in Fram (Styria), and jámovəc is used in Slovenj Gradec (Carinthia). The broader area of this dendronym is confirmed by Torre Valley dial. jám. Most likely, dial. jâm reflects a Slovenian substitute from a Middle High German base that still exists in Bavarian NHG Alme 'Ulmus'. Such relative chronology of borrowing from $M H G$ *alme 'Ulmus' must be assumed 
$-\quad$ given the area of Slovenian dendronyms and signs indicating that the borrowing took place before the dialectal lengthening of the shortened Proto-Slavic old acute in monosyllabic words of the type brät $\rightarrow$ b'ra:t. In the later development of Slovenian, the cluster - $1 \mathrm{~m}$ - was simplified to -m-, most likely even before the change $1>$ un; thus SIn. *äłm > *äm. Similar phonetic development is indicated by the Ebriach (Carinthian) adjective há:mužən (f. -žna) 'touching, incapable, weak-minded'; cf. the preservation of the Old High German loanword in Sln. álmožna 'alms'. The initial j- in jâm is thus prothetic as in the German loanword jamati 'to measure the contents of a barrel using a measuring stick or ama' $\leftarrow$ âmati 'idem'. According to Slovenian phonetic development, the variant jân for 'Ulmus', known only in Fram (Styria), could not have derived from jâm because the development - $\mathrm{m}>$ -n is unknown in this area. The final -n in jân compared to jâm can be explained with German phonetics; i.e., the Bavarian development -m > -n. On the basis of this Bavarian phonetic phenomenon and frequent apocope in German, it can be presumed that the dendronym *aln 'Ulmus' $(<M H G$ *alm) was present in Bavarian Middle High German.

Based on the explanation of SIn. jâm and jân, it is possible that Sln. läm, which is still preserved in the Bovec dialect in the reduced nominative form 'lęm (gen. lá:ma, lá:mę) 'elm', reflects a loanword from the same Middle High German base as jâm, except that the Slovenian substitute *äłm underwent metathesis, resulting in läm.

Helena Jazbec

Inštitut za slovenski jezik Frana Ramovša ZRC SAZU

Novi trg 2, 1000 Ljubljana

jazbec@zrc-sazu.si

Metka Furlan

Inštitut za slovenski jezik Frana Ramovša ZRC SAZU

Novi trg 2, 1000 Ljubljana 